\title{
La tomografía computarizada cone beam en la ortodoncia, ortopedia facial y funcional
}

\section{Cone beam computed tomography use in orthodontics, functional facial orthopedics}

Gina D Roque-Torres ${ }^{1, a, e}$, Abraham Meneses-López ${ }^{2, a} b, c, d, g$, Frab Norberto Bóscolo ${ }^{1, a, e, f, g}$, Solange María De Almeida $^{l, a, e, f, g}$, Francisco Haiter Neto ${ }^{l, a, e, f, g}$

\section{RESUMEN}

La Tomografía Computarizada Cone Beam (TCCB) es una tecnología en rápido desarrollo que proporciona imágenes de alta resolución espacial del complejo craneofacial en tres dimensiones (3D). Durante la última década, el número de publicaciones relacionadas a la TCCB en la literatura se ha incrementado de manera significativa, pero la cuestión fundamental es si esta tecnología conduce a mejores resultados.

La TCCB y su aplicación en la ortodoncia es muy importante ya que esta nueva tecnología va evolucionando cada vez más rápido y nuevas imágenes se necesitan para responder algunos casos como los de recidiva. La imagen tomográfica nos va permitir tener una visión diferente comparando con las imágenes convencionales, y esta visión va de la mano con los movimientos realizados para la corrección de la maloclusión o desproporción facial.

PALABRAS CLAVE: Tomografía computarizada por rayos X, ortodoncia, ortopedia. (DeCS, BIREME)

Departamento de Diagnóstico Oral, Facultad de Odontología de Piracicaba, Universidad Estadual de Campinas. Piracicaba, Brazil.

Departamento Académico del Niño y el Adolescente. Facultad de Estomatología Roberto Beltrán, Universidad Peruana Cayetano Heredia.

Lima, Perú.

Cirujano Dentista.

Especialista en Ortodoncia

Magister en Estomatología

Doctor en Estomatología.

Magister en Radiología Oral.

Doctor en Radiología Oral.

Profesor. 


\section{SUMMARY}

Cone Beam Computed Tomography (CBCT) is a rapidly evolving technology that provides high spatial resolution of the craniofacial complex in three dimensions (3D). During the last decade, the number of publications related to $C B C T$ in the literature has increased significantly, but the fundamental question is whether this technology leads to better results.

$C B C T$ and the application in orthodontics is very important as this new technology evolves ever faster and new images are needed to answer some cases, for example cases of recurrence. The tomographic image will allow us to give a different view compared to conventional images, and this view goes hand in hand with the movements for correcting malocclusion or facial disproportion.

KEYWORDS: Tomography, $x$-ray computed, orthodontics, orthopedics. (MeSH, NLM)

\section{INTRODUCCIÓN}

Ortodoncia y ortopedia dentofacial son áreas relacionadas con el tratamiento para la corrección de las diferentes maloclusiones y desproporciones faciales debido a discrepancias dentales $\mathrm{y} / \mathrm{o}$ esqueléticas para producir mejoras estéticas, funcionales y psicosociales (1).

Durante el tratamiento, los dientes reciben fuerzas que lo mueven en los tres planos del espacio: transversales, sagitales y verticales. De este modo, podemos diferenciar entre: el movimiento del hueso alveolar en dirección transversal (ej. expansión maxilar), en dirección anteroposterior (ej. Con los aparatos de tracción extraoral), movimientos dentales aislados, como los movimientos de inclinación y del cuerpo dentario por completo en dirección vertical (ej. intrusión y extrusión). Para todo esto, el ortodoncista debe tener conocimiento real de la anatomía del paciente para determinar las mejores fuerzas de vector para alcanzar el correcto posicionamiento de los dientes (2).

\section{REVISIÓN DE LITERATURA}

\section{Evolución de los exámenes por imágenes}

El diagnóstico por imagen en la ortodoncia se ha basado durante muchos años en las radiografías panorámicas, periapicales, carpales y oclusales. Estos exámenes como sabemos proporcionan imágenes bidimensionales de estructuras tridimensionales y se han utilizado para establecer el diagnóstico y la planificación del tratamiento de los pacientes ortodónticos, permitiendo la evaluación de la relación dental, el esqueleto maxilofacial y el tejido blando. Sin embargo, en casos seleccionados la información bidimensional (2D) puede dejar algunas preguntas sin respuesta, como en el caso de recidivas (2).

Las imágenes para los pacientes de ortodoncia deben ocurrir en 3 pasos: a) Selección de la técnica de imagen más adecuada para este paciente, b) Adquisición de la imagen adecuada, e c) Interpretación de la imagen obtenida: (1)

Siguiendo la norma de ALARA "As Low As Reasonably Achievable" que dice " tan bajo como sea razonablemente alcanzable", en los Estados Unidos sugieren que "el juzgamiento clínico se debe utilizar para determinar la necesidad y el tipo de imágenes radiográficas necesaria para la evaluación y/o monitoreo del crecimiento del paciente y del desarrollo dentofacial". Por otra parte, en la Unión Europea y el Reino Unido indican que "las imágenes presentan algoritmos en la decisión clínica basada principalmente en la edad de los pacientes (menores de 9 años de edad) y la presentación clínica (retraso en la erupción o erupción ectópica, apiñamiento o discrepancia antero-posterior, como overjet $\mathrm{u}$ overbite, etc) (1).

Como las modalidades actuales de tratamiento de ortodoncia se están convirtiendo cada vez más sofisticadas, la necesidad de registros tridimensionales (3D) precisos de los pacientes se vuelve cada vez más crítica, y la adopción de la Tomografía Computarizada (TC) ha llevado a los ortodoncistas a un cambio de paradigma con respecto a la medios de 
diagnóstico por imagen, incluyendo posibles cambios en la planificación de los tratamientos de ortodoncia y ortodoncia-quirúrgica. Por lo tanto, parece que estamos en el umbral de un cambio importante en la ortodoncia, donde el aprendizaje de las técnicas de evaluación en tres dimensiones ya son viables (3).

\section{Tomografía computarizada de haz cónico o Cone Beam (TCCB)}

Debemos tener en cuenta si el paciente es un adulto o un niño. La TCCB proporciona dos características únicas en la práctica ortodóntica: a) Las proyecciones planas (reconstrucciones de las telerradiografías) o proyecciones curvas (reconstrucciones panorámicas) que actualmente se utilizan para el diagnóstico ortodóntico, análisis cefalométricas y planificación del tratamiento, se puede obtener a partir de una única adquisición de la TCCB, b) Las imágenes base de la TCCB se pueden reconstruir para proporcionar una sola imagen antes indisponible en la práctica ortodóntica (1).

\section{Evaluaciones basadas en evidencia}

Aunque la TCCB ha aumentado la confianza en el diagnóstico ortodóntico y ha demostrado eficacia clínica en la planificación del tratamiento de caninos superiores impactados, en la evaluación de los cambios delhuesoalveolar, dientesnoerupcionados,reabsorción radicular severa y discrepancias esqueléticas severas. Ningún beneficio fue demostrado para detectar anomalías de la articulación temporomandibular, en la evaluación de las vías aéreas o apiñamientos. Pocos autores mostraron altos niveles de evidencia sobre el impacto de la TCCB en las decisiones de diagnóstico y planificación del tratamiento de ortodoncia (4-7).

Por otro lado, de acuerdo con las imágenes de la TCCB en la ortodoncia donde los dos tamaños de voxel más utilizados son $0,3 \mathrm{~mm}$ y $0,4 \mathrm{~mm}$, los cuales no presentan resolución espacial suficiente para evaluar los cambios en el hueso alveolar. Un tamaño menor del voxel sería lo más adecuado para dichos estudios pero eso aumentaría la dosis de radiación. La presencia de ruido asociado con un campo de visión extendido frecuentemente utilizado en ortodoncia, disminuye la resolución espacial y está contraindicado en los estudios de cambios en el hueso alveolar (3).

\section{Consideraciones de la dosis de radiación en ortodoncia}

Como sabemos, hay dos posibles efectos nocivos de la radiación ionizante: los efectos determinísticos (que causan la muerte celular por sobredosis en cortos períodos de tiempo que suele ocurrir después que el umbral es alcanzado, que no ocurre con una dosis única ej. mucositis) y los efectos estocásticos (efecto que altera las células de forma irreversible alterando el ADN de la célula y a diferencia del determinístico se trata de una acumulación de la dosis) (1).

La dosis eficaz para la TCCB utilizada para la documentación de ortodoncia es especialmente preocupante, especialmente porque la edad donde se inicia el tratamiento de ortodoncia es en una etapa pediátrica. Como se muestra en la Tabla 1, donde se estima que los niños pueden ser de dos a diez veces más propensos a una carcinogénesis inducida por la radiación comparada con los adultos. En conclusión, se puede decir que para todos los procedimientos de imagen que utilizan radiación ionizante, los beneficios clínicos deben sopesarse contra el potencial riesgo de la radiación, que son determinados por la radiosensibilidad relativa de los que están siendo analizados y las habilidades de los operadores para el control de la exposición a la radiación (1).

Directrices para la tomografía computarizada cone beam en ortodoncia por la Academia Americana de Radiologia Oral y Maxilo facial

\section{Imagen fiel de acuerdo con la situación clínica:} (1)

Basándose en el principio de ALARA:

1.1 La TCCB debe basarse de acuerdo a la historia del paciente, examen clínico, radiografías anteriores y la presencia de condiciones clínicas; en las que se justifica el beneficio de la dosis de radiación mayor.

1.2 Utilizar la TCCB cuando la interrogante no se puede responder con imágenes bidimensionales.

1.3 Evitar el uso de la TCCB cuando existe una modalidad alternativa no ionizante la cual puede ayudar en el diagnóstico.

1.4 Utilizar el protocolo correcto (FOV (campo de visión), minimizar la exposición, número de imágenes base, y resolución). 
1.5 Evitar el uso de TCCB sólo para obtener las telerradiografías o las reconstrucciones panorámicas.

1.6 Evitar el uso de imágenes en 2D si el examen clínico indica una TCCB.

Para la ortodoncia existen recomendaciones específicas, como se muestra en la Tabla 2. Donde se puede observar que las recomendaciones incluyen la fase de tratamiento (antes, durante y después), la dificultad del tratamiento, y la presencia de condiciones esqueléticas y dentales.

\section{Evaluar el riesgo de la dosis de radiación: (1)}

El riesgo de la radiación ha sido frecuentemente estimado mediante el cálculo de la dosis efectiva de la TCCB (Tabla 1) y este valor ha sido comparado con:

1) Las mediciones obtenidas a partir de métodos de imágenes comparables (por ejemplo, múltiples imágenes panorámicas o TC Multi-Slice médica).

2) El tiempo de radiación equivalente (por ejemplo, días pasados).

3) La radiación propiamente dicha (por ejemplo, la probabilidad de cánceres por cada escaneamento de la tomografía llamada tasa estocástica de cáncer).

2.1 Considerar el nivel de radiación relativa (Tabla 2) de acuerdo con cada protocolo diferenciando por aparato radiológico que fue usado, se puede colocar este ejemplo donde un protocolo usa tres imágenes digitales de radiografías panorámicas (Planmeca PM Proline 2000 [dosis baja]) antes, durante y después del tratamiento, donde la dosis es de 12 $\mathrm{mSv}$ por cada exposición, haciendo un total de 36 $\mathrm{mSv}$ y dos radiografías cefalométricas laterales antes y después del tratamiento, con una dosis de $5.6 \mathrm{mSv}$ por cada exposición haciendo un total de
11,2 mSv. La dosis efectiva para este protocolo de ortodoncia es $47,2 \mathrm{mSv}$, lo que representaría un RRl (Nivel de radiación relativa) para un adulto mientras que para un niño seria de dos RRI.

Esto puede ser comparado al protocolo alternativo para ortodoncia que incorpora una TCCB con campo de visión grande (i-CAT Next Generation [16x13 cm]) que tiene una dosis de $83 \mathrm{mSv}$; dos imágenes digitales (Planmeca PM Proline 2000) de radiografías panorámicas (durante y después del tratamiento) con una dosis de $12 \mathrm{mSv}$ haciendo un total de $24 \mathrm{mSv}$ y una radiografía cefalométrica lateral (después del tratamiento) con una dosis de radiación de 5,6 $\mathrm{mSv}$. La dosis efectiva para protocolo de ortodoncia es 112,6 mSv. Si bien el nivel de radiación relativa (RRL) utilizando TCCB en este ejemplo es tanto para el adulto y el niño es el mismo nivel, este protocolo ofrece más del doble de la dosis absoluta del protocolo de imágenes convencionales y eleva el riesgo de que el adulto se encuentre en una categoría superior (1) (Figura 1).

2.2 Cómo la radiación ionizante puede aumentar el riesgo de algunos pacientes (embarazadas o niños) se deben explicar los riesgos y beneficios, así como las alternativas de imágenes con otras técnicas (1).

\section{Minimizar la exposición del paciente a la radiación: (1)}

Dependiendo del tipo de equipo y las preferencias del operador, el operador puede cambiar la dosis de radiación para los pacientes, ajustando los parámetros de exposición (por ejemplo, kilovoltage, miliamperios, etc), en la calidad de imagen (por ejemplo, número

Tabla 1: Estimaciones de las del nivel de radiación relativa para los niños y adultos para imágenes de ortodoncia. (1)

\begin{tabular}{|c|c|c|}
\hline \multirow{2}{*}{$\begin{array}{l}\text { Nivel de radiación } \\
\text { relativa }\end{array}$} & \multicolumn{2}{|c|}{ Rango estimado de la dosis efectiva (mSv) } \\
\hline & Adulto & Niño \\
\hline 0 & 0 & 0 \\
\hline & $<100$ & $<30$ \\
\hline 8 & $100-1000$ & $30-300$ \\
\hline 888 & $1000-10000$ & $300-3000$ \\
\hline $8<8<8$ & $10000-30000$ & $3000-10000$ \\
\hline
\end{tabular}

Fuente: American Academy of Oral and Maxillofacial Radiology (1). 
Tabla 2: Recomendaciones de la selección de imágenes para el uso de la tomografía computarizada de haz cónico en ortodoncia (1).

\begin{tabular}{|c|c|c|c|c|c|c|c|c|c|c|}
\hline \multicolumn{3}{|c|}{ Tratamiento } & \multicolumn{8}{|c|}{ Condiciones Clínicas } \\
\hline 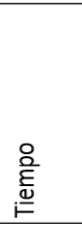 & 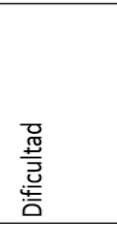 & 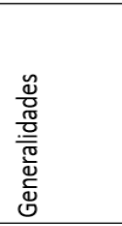 & 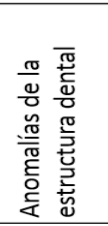 & 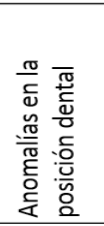 & 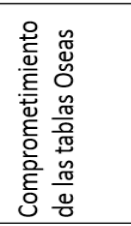 & 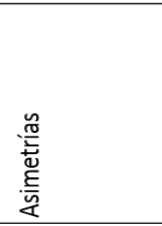 & 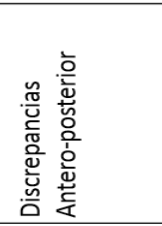 & 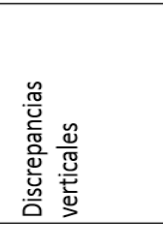 & 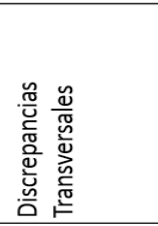 & 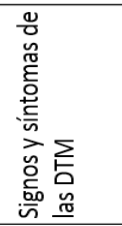 \\
\hline \multirow[t]{3}{*}{ Antes } & Leve & IIII & FOV s (I) & FOV s (I) & FOV s, m (II) & FOV $\mathrm{m}, \mathrm{I}$ (II) & FOV $m, I$ (II) & FOV $\mathrm{m}, \mathrm{I}$ (II) & FOV $m, I$ (II) & FOV $s, m$ (III) \\
\hline & Maderado & FOV $\mathbf{m}$, I (II) & FOV s (I) & FOV s (1) & FOV s, m (II) & FOV $m, I$ (II) & FOV $\mathrm{m}, \mathrm{I}$ (II) & FOV $\mathrm{m}, \mathrm{I}$ (II) & FOV $m, I$ (II) & FOV $\mathrm{m}, \mathrm{I}$ (II) \\
\hline & Severo & FOV I (II) & FOV s (1) & FOV s (1) & FOV s, m (II) & FOV $\mathbf{m}, \mathrm{I}$ (II) & FOV m, I (II) & Fov m, I (II) & FOV $\mathbf{m}, \mathrm{I}$ (II) & FOV $\mathrm{m}, \mathrm{I}$ (II) \\
\hline Durante & & III & FOV S (III) & FOV S (II) & FOV s, m (II) & $\begin{array}{l}\text { Pre - quirúrgico } \\
\text { FOV m, I (II) }\end{array}$ & $\begin{array}{l}\text { Pre - quirúrgico } \\
\text { FOV } \mathrm{m}, \mathrm{I} \text { (II) }\end{array}$ & $\begin{array}{l}\text { Pre - quirúrgico } \\
\text { FOV m, I (II) }\end{array}$ & $\begin{array}{l}\text { Pre - quirúrgico } \\
\text { FOV m, I (II) }\end{array}$ & FOV $\mathrm{m}, \mathrm{I}$ (II) \\
\hline Después & & III & FOV s (III) & FOV s (III) & FOV s, m (III) & FOV $\mathrm{m}, \mathrm{I}$ (II) & FOV $\mathrm{m}, \mathrm{I}$ (II) & FOV m, I (II) & FOV $\mathbf{m}, \mathrm{I}$ (II) & FOV $\mathrm{m}, \mathrm{I}$ (III) \\
\hline
\end{tabular}

$\mathrm{FOV}=$ campo de visión, $\mathrm{FOVs}=$ campo de visión pequeño, $\mathrm{FOVm}=$ campo de visión mediano, $\mathrm{FOVl}=$ campo de visión grande, $\mathrm{I}=$ Indicado, $\mathrm{II}=$ Posiblemente indicado, $\mathrm{III}=$ No Indicado.

Fuente: American Academy of Oral and Maxillofacial Radiology (1).

de imágenes, la resolución y la trayectoria del arco) y por último en la colimación del haz (por ejemplo, campo de visión).

3.1 Realizar TCCB con parámetros de adquisición bien ajustados y de buena calidad de imágenes para obtener las informaciones de diagnóstico deseado.

3.2 Reducir el tamaño del campo de visión para coincidir con la región de interés.

3.3 Utilizar el blindaje de protección del paciente (delantales y considerar el uso de escudos de tiroides), para minimizar la exposición a los órganos radiosensibles fuera del campo de visión.

3.4 Asegúrese de que todos los equipos de la TCCB esten correctamente instalados, calibrados y actualizados, y que cumpla con todos los requisitos y las regulaciones gubernamentales.
4. Mantener la competencia profesional en la realización e interpretación de estudios tomográficos: (1)

Los cirujanos dentistas que ordenen o realicen la TCCB para los pacientes de ortodoncia son responsables de la interpretación de todo el volumen, así como son responsables de la interpretación de todas las regiones de otras imágenes radiográficas que ordenan.

4.1 Los cirujanos dentistas tienen la obligación de lograr y mejorar su competencia profesional mediante el aprendizaje permanente a lo largo de la vida en relación con las imágenes tomográficas, bien como en interpretar las imágenes resultantes de este tipo de modalidad de imagen.

4.2 Los cirujanos dentistas tienen responsabilidades

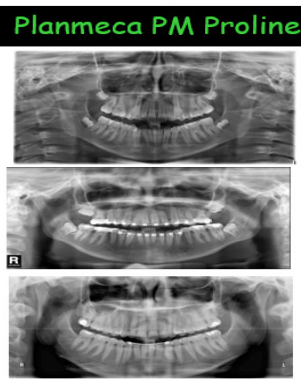

12 uSv $\times 3=36$ uSv

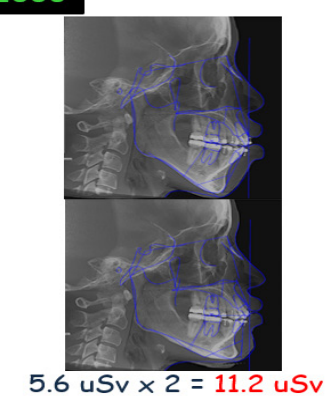

47.2 uSv = Adulto Niño

\section{i-CAT Next Generation $(16 \times 13 \mathrm{~cm})$}

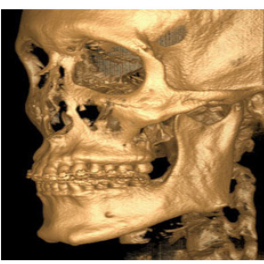

83 uSv

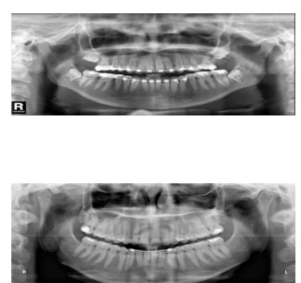

12 uSv $\times 2=24$ uSv

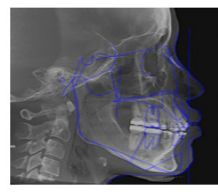

5.6 uSv

$$
112.6 \text { uSv }=\underset{\text { Niño }}{\text { Adulto } 8}
$$

Figura 1. Comparación entre un protocolo con imágenes convencionales y el protocolo 3D. 
legales al operar el equipo de TCCB y en la interpretación de las imágenes tomográficas.

4.3 Es importante que los pacientes o responsables sepan acerca de las limitaciones de la TCCB con respecto a la visualización de tejidos blandos, artefactos y el ruido.

El proceso de diagnóstico y planificación del tratamiento en ortodoncia empieza en el momento que el paciente llega a la consulta inicial. Después de la evaluación clínica y la anamnesis, pedimos pruebas adicionales y el paciente es referido a la obtención de la documentación de ortodoncia que consiste en la telerradiografía, radiografía panorámica, periapical, modelos de yeso y fotografías intra y extraorales (1).

Hoy en día, muchas oficinas de ortodoncia están reemplazandolasimágenes de ortodoncia tradicionales para todos los pacientes para su documentación en 3D que tiene características especiales. Consiste en la adquisición de la TCCB, fotografías convencionales o fotografías en 3D obtenidas por medio de escáneres o mediante un método conocido como la cartografía 2D, modelos convencionales o digitales $3 \mathrm{D}$.

Imágenes convencionales de radiografía panorámica, telerradiografías y radiografías periapicales también se pueden obtener a partir de la TCCB y también hacen parte de la documentación en 3D, (3) mientras que otros están agregando este tipo de imagen sólo en ciertos tipos de casos, como aquellos que tienen los caninos impactados o en pacientes que requieren cirugía ortognática. (8) Algunas de las diversas aplicaciones clínicas de nuevas tecnologías para el diagnóstico en 3D ha demostrado que el uso de la TCCB en ortodoncia ha ido creciendo y en aplicaciones tales como cefalometría, instalación de mini implantes, diagnóstico oportuno de reabsorciones radiculares, análisis de las vías aéreas, entre otros. De esa forma, a continuación será demostrado de forma esquemática y resumida cuales son las aplicaciones clínicas en la ortodoncia, ortopedia facial y funcional (1).

\section{Aplicación de tomografía computarizada cone beam en el diagnóstico ortodontico}

\section{Cefalometría 3D}

La cefalometría, que se originó a partir de la craneometría, fue desarrollada a partir de una técnica antropológica para cuantificar la forma y tamaño del cráneo, casi 40 años después del descubrimiento de los rayos X por Roentgen en 1895, lo cual revolucionó la medicina y odontología (9).

La cefalometría tradicional en dos dimensiones, también conocido como roentgenografía cefalométrica, se introdujo en la odontología por Broadbent en 1931 $\mathrm{y}$ desde entonces se ha mantenido relativamente sin cambios. Desde esos primeros años, cefalogramas fueron ampliamente utilizados como una herramienta para la investigación clínica, del desarrollo y de los efectos del tratamiento y sus resultados (9).

Más allá de su uso como una herramienta para el diagnóstico, los errores inherentes a la cefalometría y su posterior análisis están bien documentados. Los errores significativos están asociados con la ambigüedad en la localización de estructuras anatómicas, por la falta de características anatómicas bien definidas, contornos, sombras y la variación en la posición del paciente. Por otra parte, Macri y Athanasios demostraron en 1997 que la recolección manual de datos y el procesamiento de análisis cefalométrico tiene una baja exactitud y precisión. Puntos anatómicos específicos como Porion y condilion, no pueden ser localizados con precisión y coherencia en las radiografías laterales y se consideran altamente inestables (10).

La cefalometría en tercera dimensión es una de las grandes promesas que esta nueva tecnología puede ofrecer; sin embargo, todavía necesitará algún tiempo hasta que tengamos el análisis 3D práctico, útil y sobre la base de una nueva investigación. Sin embargo, cefalogramas reconstruidos a partir de la TCCB no muestran diferencias estadísticamente significativas (mediciones lineales y angulares) en comparación con cefalogramas tradicionales. Reconstrucciones multiplanares (MPR) se presentan más precisos en relación con las medidas físicas, en comparación con los modos de VR (volumen rendered) y SSD (shaded surface display) (11) (Figura 2).

Las medidas cefalométricas angulares en la reconstrucción 2D y 3D derivadas de las imágenes de la TCCB son reproducibles y válidas comparándolas con las mediciones obtenidas en la telerradiografía en normo lateral (TNL), incluso con una excelente 


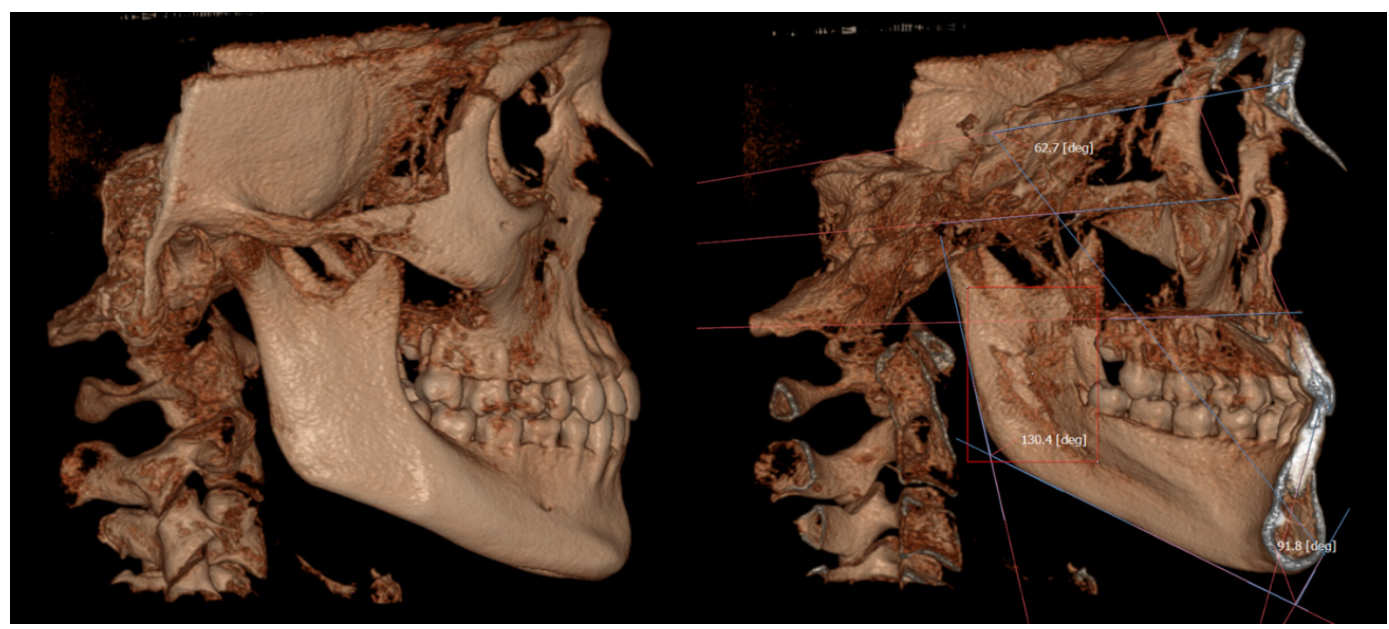

Figura 2. Cefalometría en imagen 3D de la TCCB.
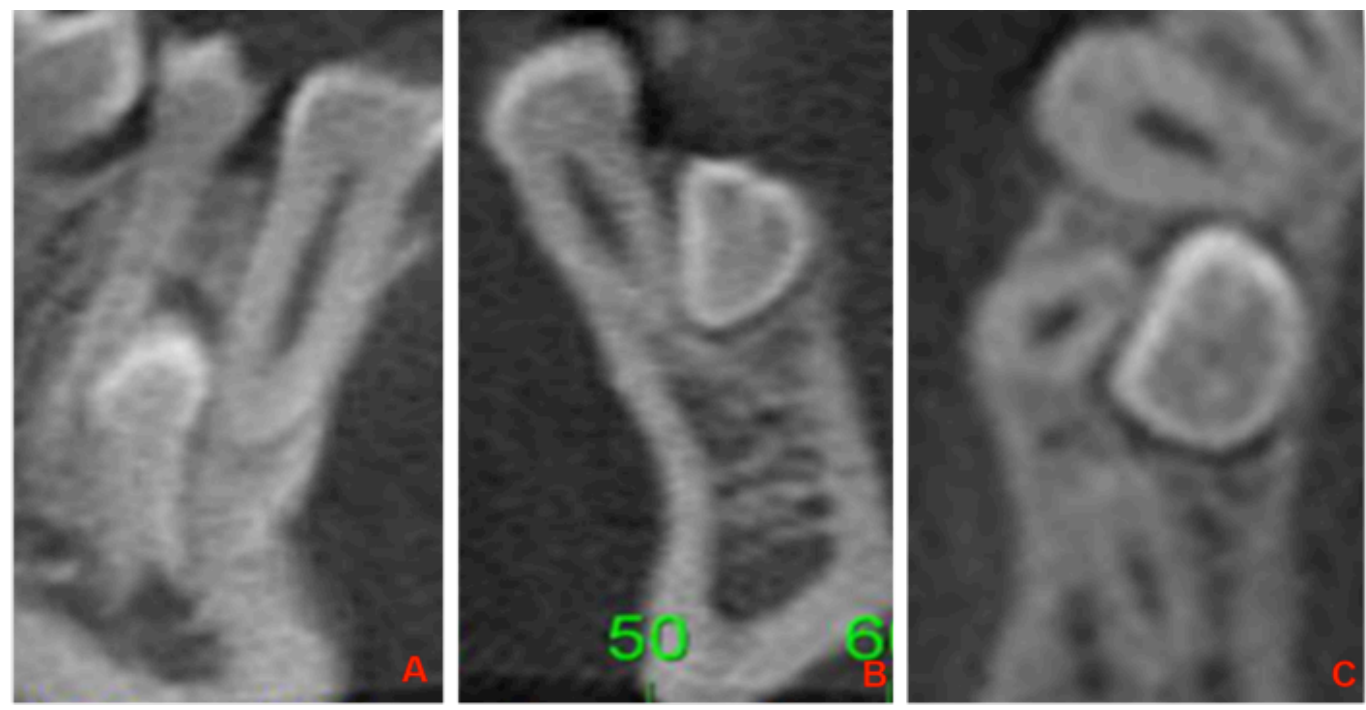

Figura 3. Pieza 33 impactada. A: Corte Sagital. B: Corte Coronal. C: Corte Axial.

correlación entre ellas; pero existen algunas diferencias que no representan valores clínicos relevantes en la evaluación cefalometría en su conjunto (12).

\section{Evaluación de dientes impactados y/o retenidos}

La proyección panorámica ofrece las mejores imágenes cuando la anatomía a ser radiografiada se aproxima a las características genéricas de la mandíbula. Sin embargo, cualquier desvió de la forma se traduce en una estructura que no está centrada en esa área focal, y la imagen resultante muestra las diferencias en el tamaño, forma y ubicación en comparación con el objeto real (13).
La ubicación de caninos se realiza usando técnicas convencionales y variadas. La técnica de paralelismo tiene una sensibilidad del $89 \%$ para un desplazamiento horizontal del foco de los rayos X y una sensibilidad del $46 \%$ para un desplazamiento vertical del tubo si el canino estuviese impactado por vestibular. Sin embargo, si el canino se encuentra en palatino, la técnica de desplazamiento horizontal y vertical del tubo tiene una sensibilidad de apenas un 63\% (13).

La impactación y erupción ectópica de caninos retenidos presenta un gran problema por la ausencia de síntomas y uno de esos problemas son las reabsorciones externas. Para Ericson y Sellhart 
alrededor del $12,5 \%$ de los caninos maxilares ectópicos causan algún grado de reabsorción en los incisivos adyacentes. En el estudio realizado por Shellhart (15) en 1998, se reportó que en más del $90 \%$ de los casos con caninos retenidos, el diente sin erupcionar es uno solo y la retención bilateral ocurría en el $8 \%$ de los pacientes (14-15).

En algunos casos la TCCB proporciona más información que la radiografía panorámica, por ejemplo en los casos de dientes retenidos e impactados, reabsorción radicular, fisuras labio-palatinas y los terceros molares, excepto por los cambios en la ATM (16).

Por ejemplo, para el diagnóstico de reabsorciones radiculares producidas por los caninos, se ha detectado que estas reabsorciones ocurren en mucha mayor proporción que la anteriormente descrita, aumentando la prevalencia a un $38 \%$ en los incisivos laterales y a un $9 \%$ en los centrales (14) (Figura 3).

En situaciones en las que el tercer molar inferior se encuentra cerca del canal mandibular, la imagen panorámica muestra $66 \%$ de sensibilidad, $74 \%$ de especificidad para la relación de los dientes con el canal (11-17).

\section{Articulación temporo-mandibular}

La medida clínica de la eficacia de cualquier prueba de diagnóstico se puede expresar como la sensibilidad y la especificidad. En pocas palabras, la sensibilidad es la capacidad de determinar la proporción de personas con una enfermedad en particular, como un resultado positivo, y la especificidad es la capacidad de determinar la proporción de personas sin la enfermedad como un resultado negativo. Sobre la base de estas expresiones de la efectividad del diagnóstico por imagen, las técnicas convencionales para obtener imágenes no son buenas para la evaluación de la articulación temporomandibular, la ortopantomografía mostró una sensibilidad de 0,64 $\pm 0,11$, mientras que la tomografía lineal resultó en una sensibilidad del $55 \pm 0.11$. La Tomografía convencional obtiene un valor de $0,58 \pm 0,15$. En contrapartida, la precisión diagnóstica de la TCCB es de $0,95 \pm 0,05$ (18)

Sin embargo, ninguna información adicional se obtuvo mediante la evaluación retrospectiva de la TCCB en $83,3 \%$ de los casos, debido a la falta de discriminación de las estructuras adyacentes. Solamente encontraron que la forma y la posición del cóndilo en la fosa glenoidea fueron considerados útiles (19).

Por otro lado, si la adquisición de la TCCB se ha logrado y como se hace generalmente con un campo de visión más grande, lo que permite la obtención de imágenes articulares en reformataciones multiplanares y en tercera dimensión, para evaluar la morfología ósea y el posicionamiento condilar en conjunto con la oclusión dentaria, el examen debe ser obtenido en intercuspidación máxima para una mejor

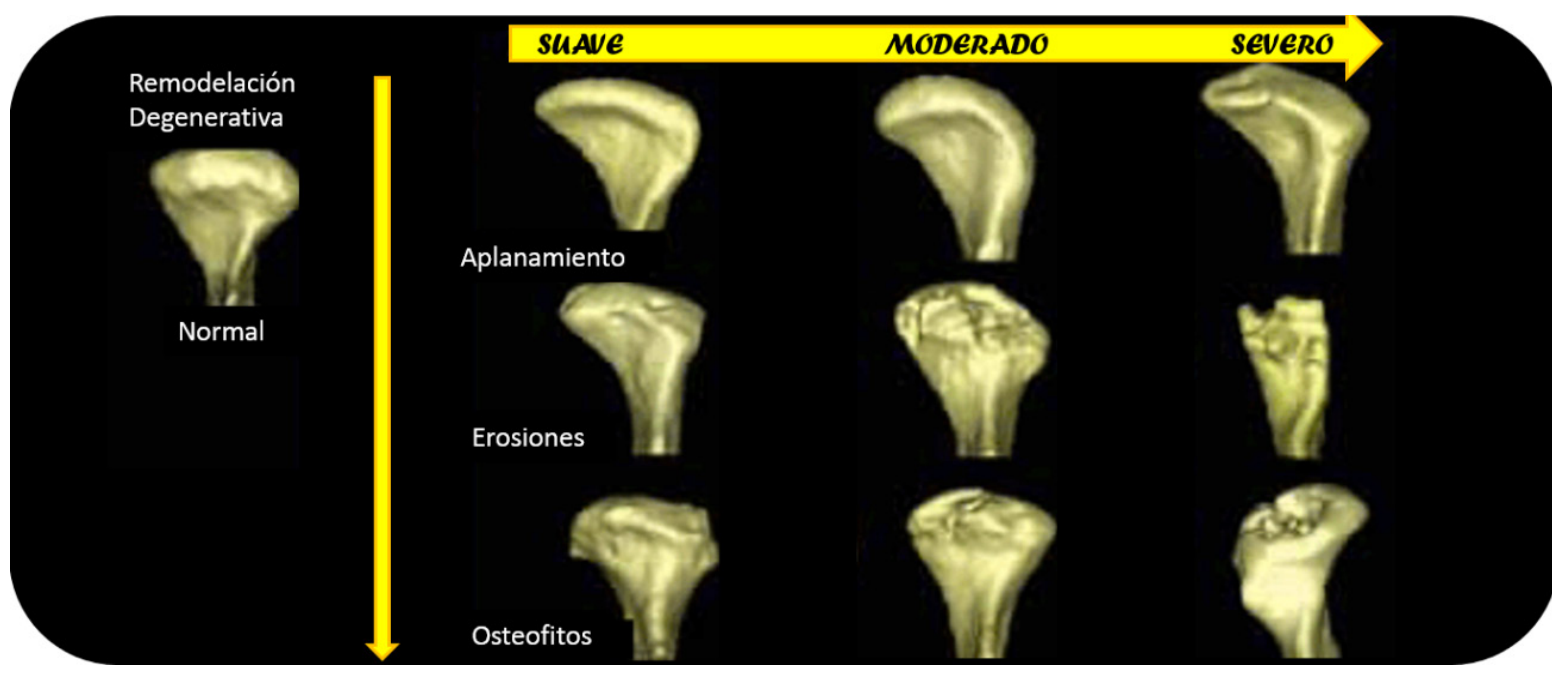

Figura 4. La articulación temporomandibular normal y su comparación con los cambios morfológicos como aplanamiento, erosiones y osteofitos. (Tomado de: http://searchpp.com/temporomandibular-joint-disorder/). 
evaluación (19).

\section{ATM anatomía (normal y patología)}

En relación con este tema la literatura es controversial ya que hay poca información disponible sobre la eficacia de los exámenes tomográficos en la mejora del diagnóstico de los trastornos temporomandibulares en comparación con la radiografía panorámica. En la literatura se pueden encontrar obras que hablan que la radiografía panorámica es una herramienta inicialaceptable para evaluar las estructuras óseas de la articulación temporomandibular (20). Sin embargo, Korbmacher y col. (21) señalan que poca información adicional se puede obtener de la TCCB en comparación con los cambios morfológicos groseros que ya puede mostrar la radiografía panorámica (Figura 4).

Cuando se comparó la TCCB, TC y radiografía panorámica en casos de erosión del cóndilo, se observó una mayor exactitud de la TCCB, 95\% (dinámica) y $77 \%$ (estático) en los escáneres tomográficos y el $65 \%$ en las proyecciones panorámicas. Frente a todo esto, es necesario tener en cuenta que la extensión de las alteraciones es proporcional a la duración y la gravedad del dolor (20).

\section{Morfología y reabsorción radicular}

La mayoría de las reabsorciones radiculares involucradas en el tratamiento de ortodoncia se pueden ver fácilmente en las radiografías periapicales $(20,22)$. Sin embargo, la reabsorción que ocurre en el lado vestibular y lingual de los dientes es difícil de evaluar y cuantificar en la vista 2D (20).

La diferencia media entre la TCCB y la visualización directa de la medida de la longitud de la raíz es de 0,05 mm (DP + / - 0,75), diferencia estadísticamente significativa para algunas raíces. In vivo: el error es menor que $0,35 \mathrm{~mm}$ (tratamiento pre y post) (23).

A pesar del cambio en el posicionamiento de los dientes, la TCCB por lo general produce una alta reproducibilidad, mejorando de este modo su utilidad en la investigación de ortodoncia (23) y los estudios muestran que el mayor movimiento de los dientes después del tratamiento ortodóntico puede estar directamente asociado con un aumento de gravedad de la reabsorción de la raíz y que la TCCB es una herramienta útil para evaluar la reabsorción radicular apical después del tratamiento ortodóntico (24) (Figura 5).

\section{Dehiscencia y fenestración}

La espesura de la cresta alveolar define los límites del movimiento ortodóntico, y desafiar esos límites puede resultar en efectos colaterales iatrogénicos para el soporte periodontal y la protección provocando a menudo dehiscencia y fenestración. Los movimientos de ortodoncia más críticos incluyen la expansión de los arcos dentales y movimientos de retracción anterior, protrusión y translación (3).

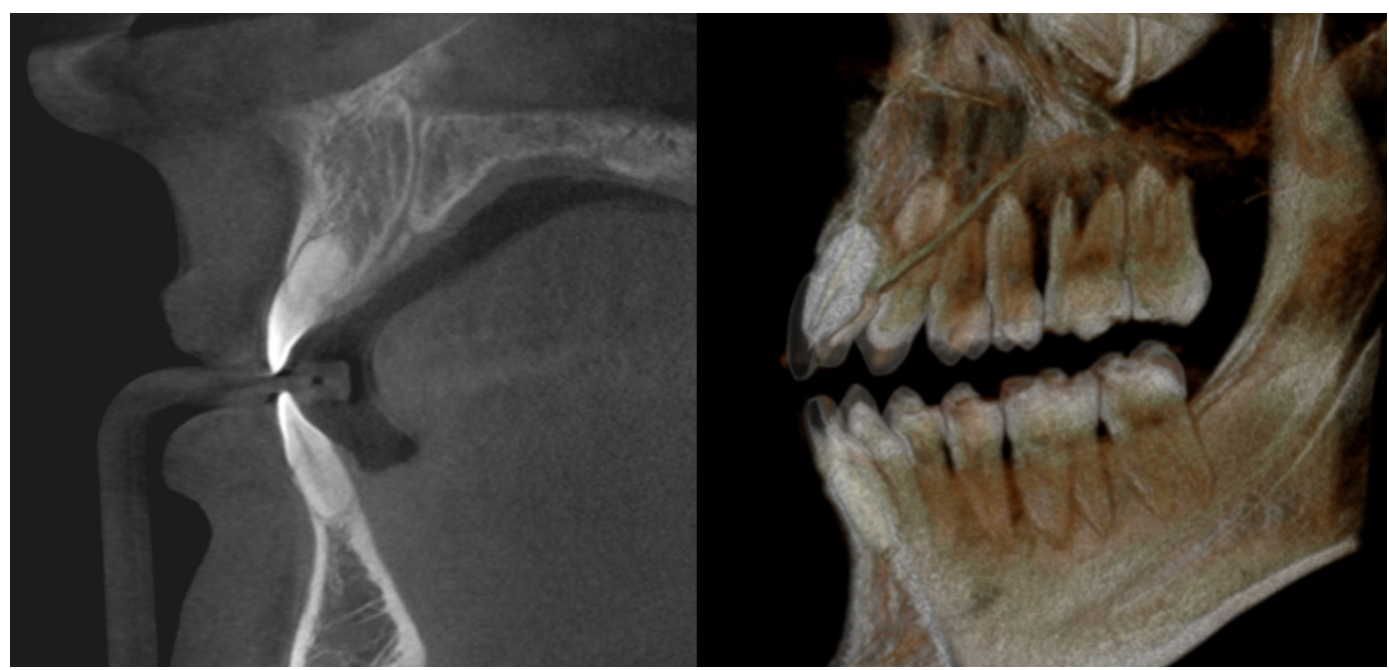

Figura 5. Presencia de reabsorción radicular en los incisivos en pacientes después de tratamiento ortodóntico evaluado mediante TCCB. 
La aparición de dehiscencias y fenestraciones durante el tratamiento de ortodoncia depende de varios factores, tales como la dirección del movimiento, la frecuencia y la magnitud de las fuerzas ortodónticas, el volumen y la integridad anatómica de los tejidos periodontales. Antes del tratamiento ortodóntico, la morfología alveolar deberá ser determinada por proyección de imagen para evitar estos problemas (25) (Figura 6). A pesar de toda la ayuda que brinda la TCCB, en el caso de un diagnóstico de dehiscencia y fenestración esta debería hacerse con precaución (11).

Sin embargo, en la literatura se puede encontrar que hay una diferencia significativa entre la fenestración entre los individuos con Clase I esquelética, Clase II y III. Además de eso, la fenestración tiene una mayor prevalencia en el maxilar superior, y la dehiscencia se encontró más en la mandíbula (26).

El patrón de crecimiento facial ejerce influencias en las características de las tablas óseas vestibular y lingual. Los braquifaciales tienen rebordes alveolares más anchos en sentido vestibulolingual comparado con los mesofaciales y dolicofaciales (27). Los dolicofaciales presentan una sínfisis mandibular y el reborde alveolar antero- inferior más estrecho que otros patrones faciales (28).

Desde esta perspectiva, en los pacientes con patrón de crecimiento horizontal (braquifacial), la planificación ortodóntica tiene menos limitaciones morfológicas para el movimiento vestibulolingual de los incisivos inferiores. Por el contrario, en los pacientes con patrón de crecimiento vertical (dolicofacial) tienen las mayores restricciones en las posibilidades de movimiento sagital de los incisivos inferiores (25).

Por otro lado, en la región de los primeros premolares se encuentra una zona progresivamente más estrecha superiormente. En esta región, frente a un movimiento de cuerpo hacia vestibular, la raíz puede atravesar el hueso alveolar más fácilmente (29).

\section{Crecimiento y desarrollo facial 3D}

Se están realizando nuevos estudios en 3D sobre el crecimiento y el desarrollo, ya que es posible la utilización de la TCCB para evaluar a niños en la dentición mixta y permanente temprana, para la obtención de medidas dentales reales en análisis de discrepancia de espacios, posiciones espaciales de las bases esqueléticas, la evaluación de las vías respiratorias y de los senos faciales (11).

\section{Dispositivos de anclaje temporal}

Los dispositivos de anclaje temporal (DATs) han ganado popularidad en los últimos tiempos por su uso en el tratamiento ortodóntico. Muchos movimientos

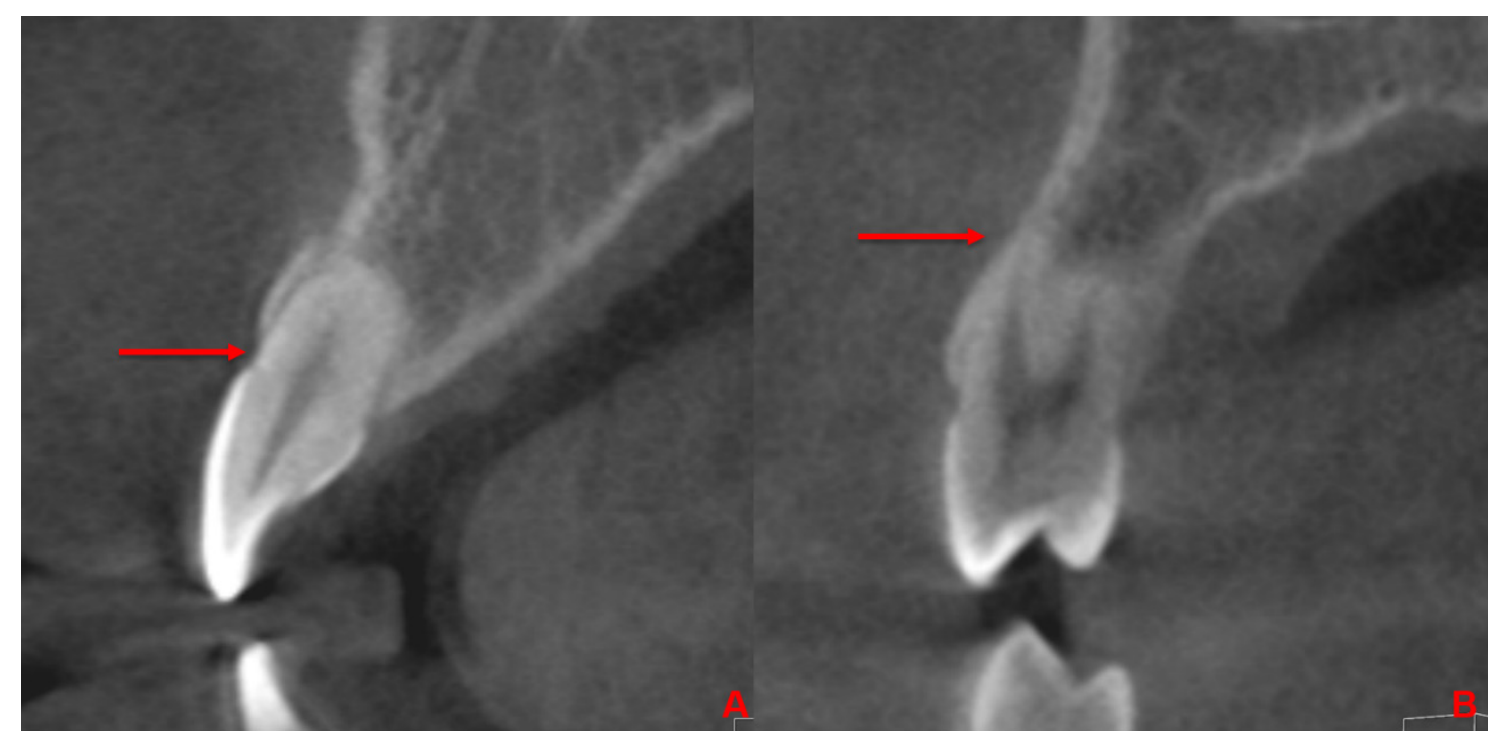

Figura 6. A: Caso de dehiscencia. B: Caso de fenestración. 
de los dientes eran mecánicamente difícil de lograr en el pasado, ahora se han logrado con el uso de estos mini- implantes, mini- pernos y placas de anclaje. Para la colocación de los DATs es importante conocer la posición de la raíz, lo cual puede aumentar el éxito del tratamiento. Imágenes tomográficas permiten visiones más precisas y fiables de las relaciones interradiculares que las radiografías panorámicas (2). Las imágenes de la TCCB permiten no sólo la colocación de más éxito, sino también para una mejor planificación, de manera que los vectores de fuerza apropiada se pueden utilizar durante el tratamiento ortodóntico. Por otra parte, los DATs pueden colocarse mediante guías quirúrgicas construidas en forma virtual y confeccionadas por medio de prototipos (3). La calidad del hueso en el sitio de colocación de DAT debe ser evaluada antes de la inserción del miniimplante. Cuantificar la espesura del hueso palatino puede ayudar a determinar el tamaño y la ubicación de los DATs, lo que puede ayudar en la planificación del tratamiento, así como saber la ubicación exacta de las estructuras adyacentes (11). (Figura 7)

El lugar ideal para la colocación de mini-implantes en la región anterior es entre los incisivos centrales y laterales en el maxilar superior y entre el incisivo lateral y el canino en la mandíbula. En la región posterior vestibular de ambos maxilares, la localización óptima es entre el segundo premolar y el primer molar y entre los primeros y segundos molares. En la región palatina posterior, la ubicación óptima es entre los primeros y segundos premolares, pues se tiene la ventaja de un mayor grosor cortical (20).

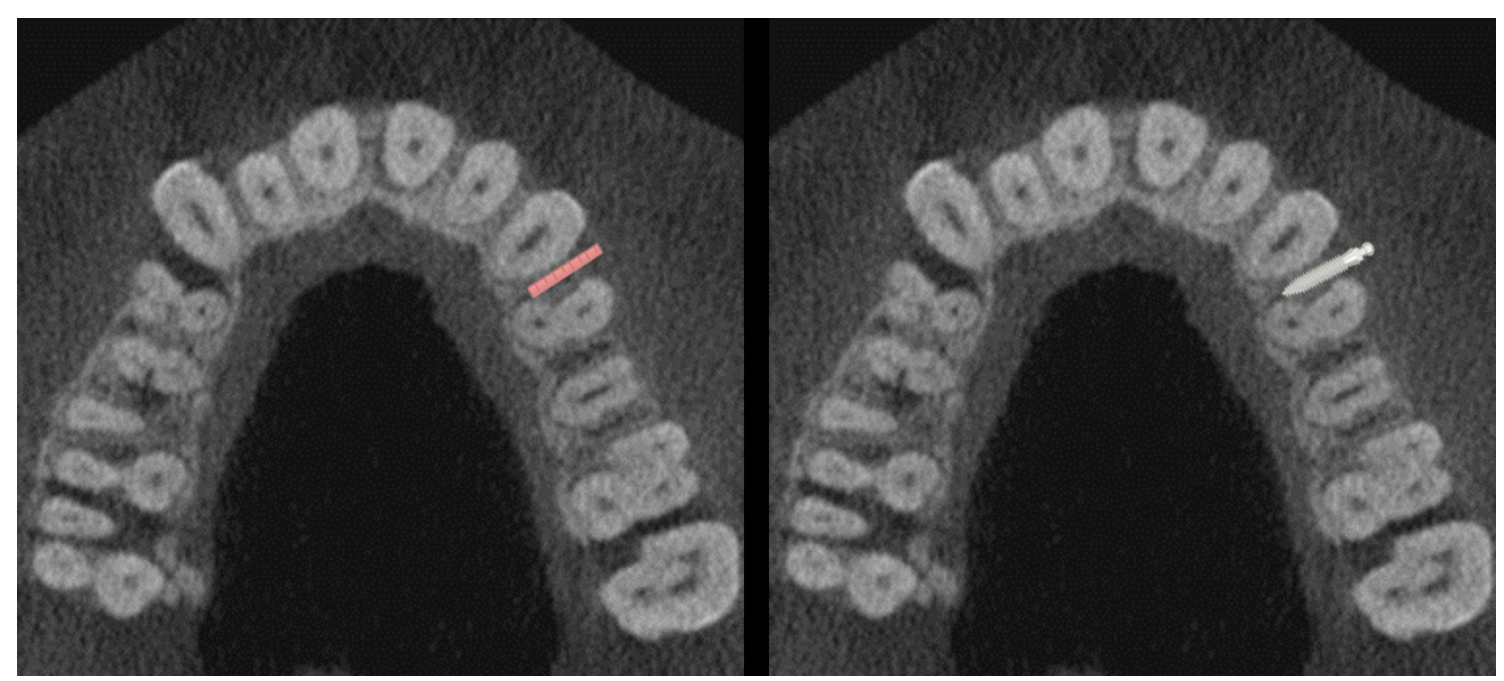

Figura 7. Evaluación de la TCCB para el correcto posicionamiento del mini-implante en una vista axial.

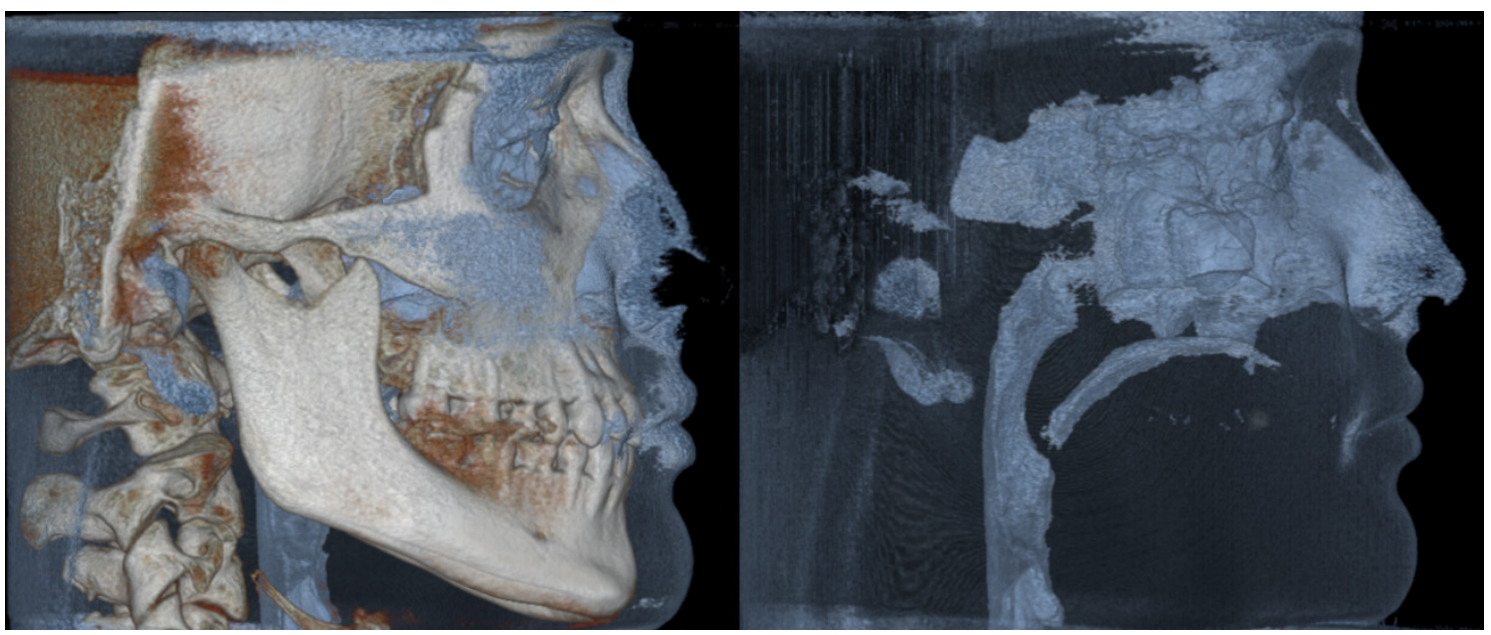

Figura 8. Reconstrucción 3D de las vías aéreas de un paciente después del tratamiento ortodóntico. 


\section{Evaluación de la vía aérea}

La apnea obstructiva del sueño (AOS) es un trastorno del sueño grave que afecta al $5 \%$ de la población mundial. Se caracteriza por ronquidos y se puede definir como el cese de la respiración durante el sueño, debido a la obstrucción mecánica por el retro-posicionamiento de la lengua en las vías aéreas, exceso de tejido en la vía aérea superiores, o el colapso parcial de la tráquea. Debido a las nuevas técnicas de imágenes de diagnóstico, evaluación tridimensional generada por la TCCB, permite la cuantificación volumétrica $3 \mathrm{D}$ de las vías aéreas más afectadas o estrechas a lo largo de toda la trayectoria espacial de las mismas (3).

Los valores volumétricos serán útiles en el diagnóstico diferencial para los casos ortodonticosquirurgicos, especialmente en casos de deficiencia esquelética de la mandíbula, pues avances mandibulares puede aumentar el volumen de las vías respiratorias (30) (Figura 7).

A pesar de la posibilidad que la TCCB proporcione la medición volumétrica de las vías respiratorias, no hay estudios que demuestren que se puede utilizar como una herramienta precisa para diagnosticar la AOS (11).

Estudios recientes $(31,32)$ indican que la disminución de la dimensión de la vía aérea en la zona del paladar blando, debido al aumento del volumen del mismo debe de ser tomado en cuenta en la planificación del tratamiento de los pacientes con AOS. Por otro lado, Alves y col. (33) demostraron que la evaluación de las dimensiones de las vías respiratorias por medio de la TCCB de la faringe, fueron significativamente mayores en los respiradores nasales que en pacientes con respiración bucal(Figura $8,9)$.

\section{Superposiciones}

Una de las tareas más difíciles en la ortodoncia es la desintegración de los componentes de crecimiento morfológicos dentales y esqueléticos que nos brindan la respuesta al tratamiento. La superposición de telerradiografías laterales ha sido la base en la cuantificación de los cambios de tratamiento y el crecimiento (34).

Pueden ser de gran utilidad en la evaluación de los resultados de ortodoncia y ortopedia, especialmente en los casos quirúrgicos (cirugía ortognática) y ortopedia en los casos de: asimetrías, discrepancias anteroposterior, verticales y transversales, utilizando la TCCB ahora como ayuda en 3D. Por otro lado, el movimiento y la expansión de la maxila también puede ser evaluada mediante la superposición de modelos digitales 3D (34).

a. Cirugía ortognática.- La TCCB es útil en la evaluación precisa en la planificación de pacientes sometidos a cirugía ortognática. Se propone que también tiene un papel en la evaluación postoperatoria de un subgrupo de pacientes que sufrieron complicaciones durante

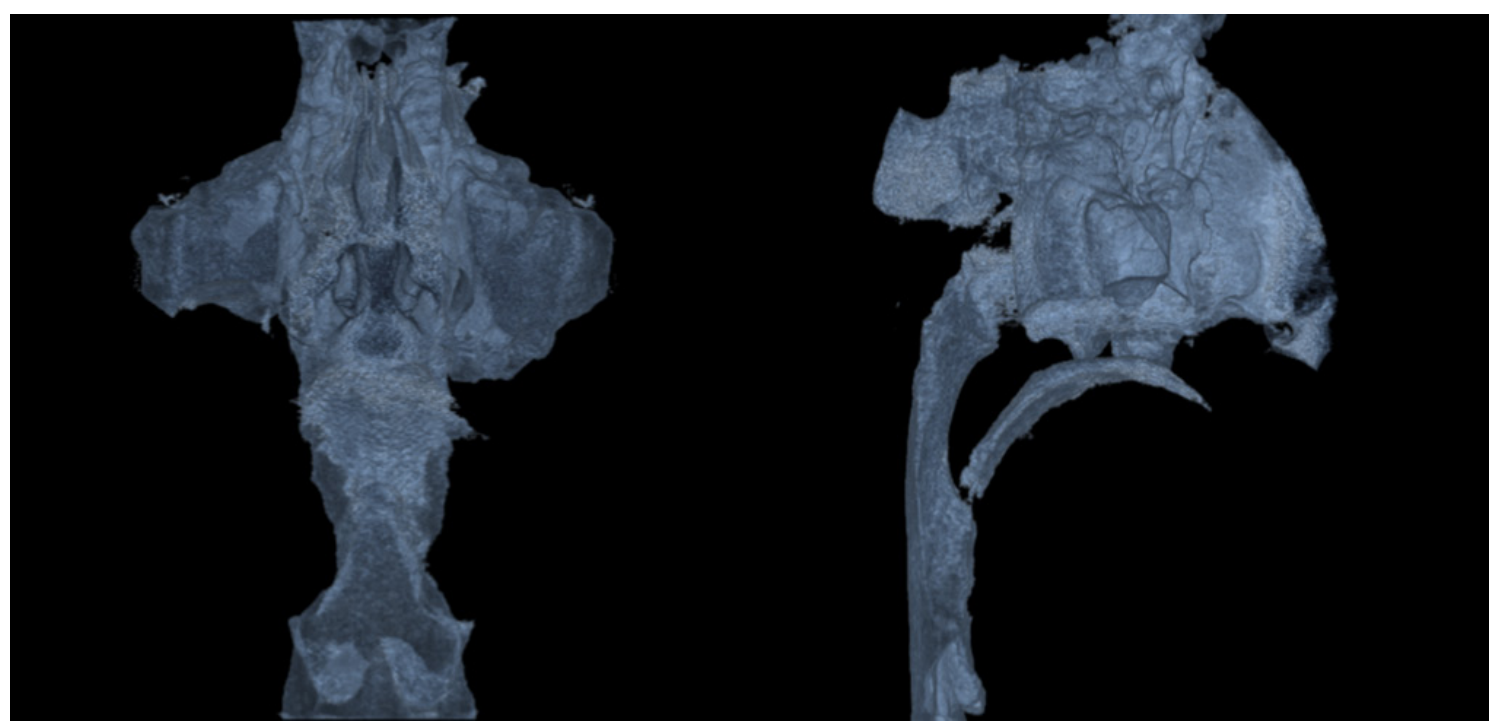

Figura 9. Evaluación del volumen de las vías aéreas mediante la TCFC en una vista frontal y lateral. 
la cirugía. La TCCB debe ser considerada para la evaluación de la mandíbula después de una fractura desfavorable cuando se considera que las radiografías simples no proporcionan información adecuada (34).

b. Asimetría.- Clínicamente, la asimetría se presenta como una desviación del mentón en la mandíbula, de la línea media dentaria y/o discrepancias oclusales significativas, así como otra asimetría dentarias y craneofaciales (34).

c. El labio leporino y fisuras labiopalatinas.- $\quad$ La TCCB estima el tamaño (dimensiones) de los defectos óseos y la relación espacial del defecto a otras estructuras anatómicas importantes que son difíciles de obtener en imágenes 2D. También proporciona las relaciones anatómicas exactas de las fisuras y el grosor del hueso alveolar alrededor de los dientes existentes en la zona de las fisuras. Esta información es muy valiosa para procedimientos de planificación para un posible injerto y para la movilidad dentaria en la dentición existente (20).

d. La expansión maxilar.- Imágenes de la TCCB de deficiencias transversales maxilares tratadas con expansores fijos o removibles reportan beneficios en la caracterización de aparatos específicos para la expansión, en los efectos dentarios asociados, y cuantificación de los cambios en las dimensiones del esqueleto de la cavidad nasal y del volumen del seno maxilar (35).

e. Discrepancias transversales.- Estas anormalidades pueden estar presentes ya sea como mordidas cruzadas o discrepancias esqueléticas en las que hay un exceso de compensación dental de inclinación vestíbulo-lingual de los dientes posteriores (20).

f. Discrepancias anteroposteriores.- Estas son la clase esquelética II y III (20).

g. Discrepancias verticales.- Patrones faciales iniciales evaluados clínicamente o radiográficamente pueden sugerir discrepancias esqueléticas clacionadas con la deficiencia o exceso en la maxila verticalmente y pueden presentar sobremordida o mordida abierta (20).

\section{Hallazgos incidentales}

Los hallazgos incidentales son muy importantes y no pueden ser ignorados en especial la información adicional brindada cuando se tiene una TCCB, ya que las imágenes $2 \mathrm{D}$ a veces pueden causar falsos positivos; por lo tanto, aumentar los costos y la ansiedad del paciente. La falta de reconocimiento de las lesiones incidentales puede traer implicaciones médico-legales por negligencia. Estos resultados sugieren que la TCCB tomada con fines de ortodoncia debe ser leída por un radiólogo oral o un ortodoncista que tenga una mejor formación (1).

Entre los hallazgos más comunes en el área maxilofacial está lo relacionado con los cambios en las vías respiratorias $(51,8 \%)$, los dientes impactados $(21,7 \%)$, ATM $(11,1 \%)$, hallazgos endodonticos $(4,3$ $\%)$ y otros (3,9\%) (36) (Figura 10).

El estudio de Drage y col. el año 2013 (37), encontró 370 hallazgos incidentales en 329

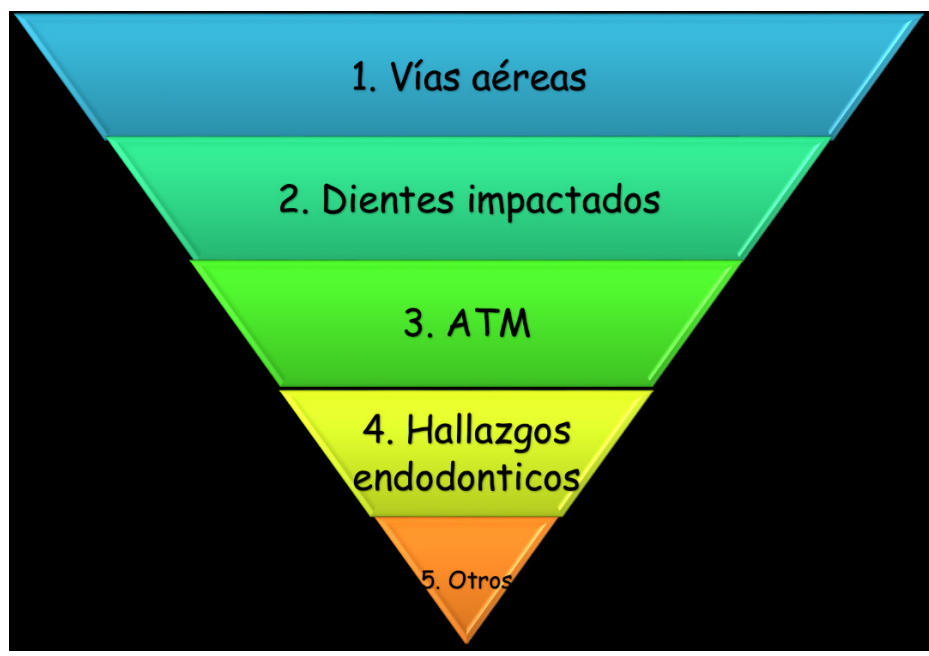

Figura 10. Hallazgos incidentales más comunes en el área maxilofacial (39). 
tomografías de pacientes de ortodoncia con al menos un hallazgo incidental en $66 \%$ de los pacientes. Los hallazgos incidentales más comunes fueron dentales (120) e incluyo raíces deciduas retenidas (24) y enfermedad periapical (15). De los 370 hallazgos, 200 no requirieron ningún seguimiento, 168 necesitaron controles, pero el plan de tratamiento ortodóntico en general no fue alterado. Sólo dos resultados fueron significativos en el tratamiento de ortodoncia que se cambió por el hallazgo incidental (37).

En un estudio reciente (38), se demostró que el ortodoncista y residentes de ortodoncia pierden cerca del $67 \%$ de las lesiones y tienen una tasa de detección del $50 \%$ de falsos positivos cuando evalúan imágenes de TCCB. Después de 3 horas de entrenamiento por un radiólogo maxilofacial oral, la tasa de error se redujo en $33 \%$ y $3 \%$, respectivamente.

Esta tasa de error es relativamente alta en comparación con los datos de patrón oro histórico para la detección de lesiones por especialistas entrenados en radiología. Otro estudio (39) demuestra que los ortodoncistas usan la TCCB en situaciones clínicas específicas como en la evaluación de dientes impactados, dientes supernumerarios, anomalías craneofaciales, evaluación de la articulación temporomandibular con un porcentaje más alto en comparación a la evaluación de las vías respiratorias maxilofacial entre otros.

\section{Diagnóstico y planificación}

La obtención de una TCCB antes del diagnóstico y planificación del tratamiento ortodóntico debe estar indicado en pacientes que tienen un diente retenido con erupción retardada en una ubicación cuestionable, reabsorción radicular severa, o una discrepancia esquelética grave. Este mismo estudio concluyó que la obtención de la TCCB para evaluar los cambios de la ATM, de las vías aéreas no dio lugar a ningún cambio significativo en el diagnóstico o plan de tratamiento (1).

La TCCB sólo debe ordenarse cuando hay una justificación clara, específica y clínica de cada paciente (40).

Como un ejemplo de justificación de la obtención de la TCCB en el caso de canino impactado, Honey y col. (41) encontraron que el plan inicial de tratamiento realizado con las imágenes $2 \mathrm{D}$ fue alterado después de la interpretación de las imágenes en 3D para más de $1 / 4$ de los dientes del estudio.

\section{El uso de la TCCB en la investigación ortodóntica}

Con el adviento de toda la tecnología, la investigación es un paso importante para que la TCCB sea más conocida y usada.

Maduración esquelética.- La maduración esquelética ayuda a los ortodoncistas en la selección del tratamiento y ver el tiempo del mismo en cada paciente. Se utiliza por lo general la radiografía carpal o telerradiografía para su evaluación. Shim y col. (41) evaluaron 98 TCCB, desde la segunda a la cuarta vértebra en individuos de 11-18 años de edad. Las TCCB fueron evaluadas a través de las etapas de maduración esquelética propuestas por Baccetti en 7 cortes sagitales. Los autores llegaron a la conclusión

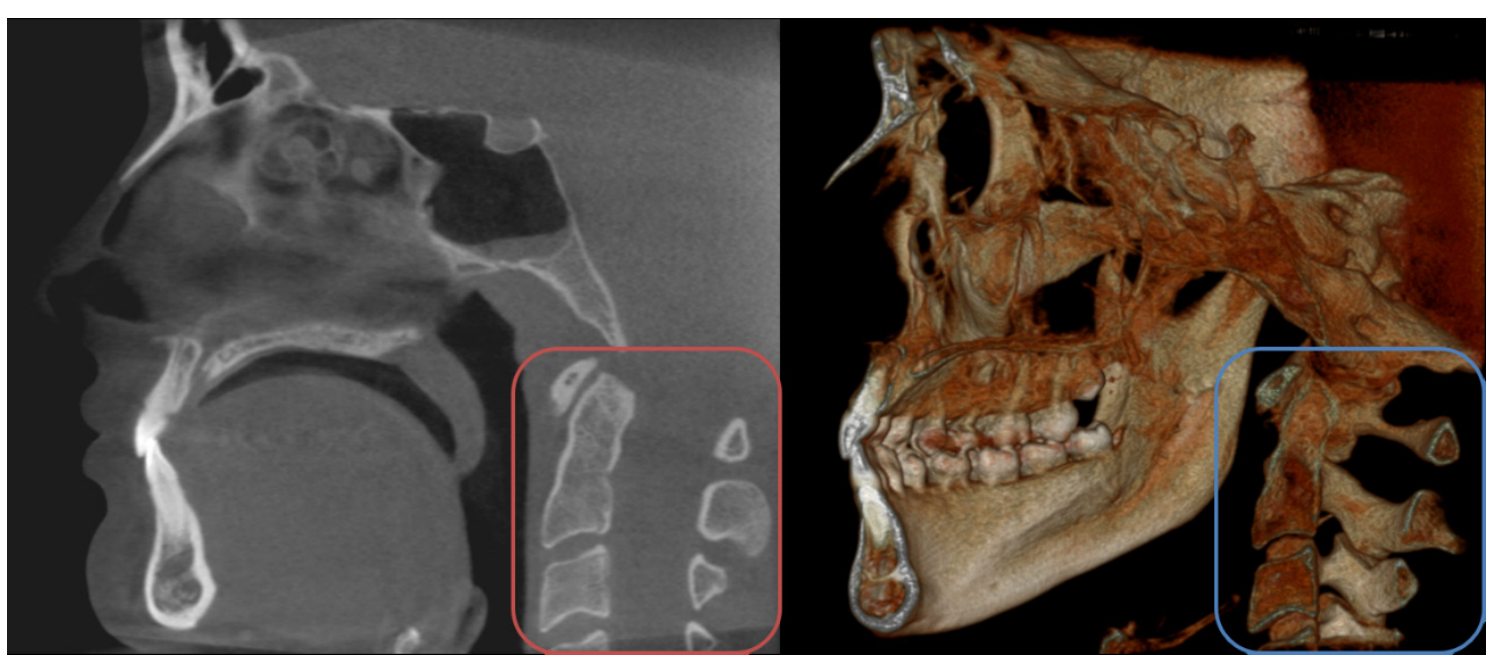

Figura 11. Evaluación de las vértebras mediante la TCCB. 
que con el método de maduración ósea, medido en la TCCB y en la telerradiografía obtuvieron el mismo resultado (Figura 11).

Elementos finitos.- El método de elementos finitos (MEF) es un análisis matemático que consiste en la discretización de un medio continuo en elementos pequeños, manteniendo las mismas propiedades del medio original (43).

El MEF puede ser utilizado en diversas áreas de las ciencias exacta y biológicas y, debido a su gran aplicabilidad y eficiencia, existen trabajos con esta metodología en diversas especialidades odontológicas, como en la Ortodoncia, cuando se desean analizar cargas, tensiones y desplazamientos provocados por el tratamiento; siendo este análisis realizado a partir de la TCCB (43).

\section{Protocolos de la TCCB en la ortodoncia sugerido} por la Academia Americana de Radiología Oral y Maxilofacial

Los protocolos para las imágenes de TCCB deben tener en consideración las ventajas relativas de esta tecnología sobre las radiografías convencionales, incluyendo la calidad de la información recopilada, su impacto potencial en el diagnóstico, la planificación del tratamiento, la facilidad de su uso versus el riesgo, incluyendo la exposición a la radiación y costos financieros (1).

Hablando específicamente de la TCCB debemos considerar el campo de visión (FOV), evaluar la particularidad del caso e interpretar en múltiples cortes (1).

El proveedor debe decidir cuál es la imagen que él o ella está tratando de lograr para el paciente. El campo de visión puede ser pequeño (solo diente o sector), medio (ambos arcos, incluyendo ATM) o grande (cabeza completa) (1).

El FOV más pequeño se utiliza para evaluar los dientes individuales; por ejemplo, dientes retenidos, morfología de la raíz, etc. o de los sitios para la colocación de implantes dentales o DATs (1).

EL FOV mediano incluye la mandíbula, maxilar o ambos, y normalmente se utiliza cuando es necesario obtener información adicional acerca de las relaciones oclusales, asimetría facial, evaluaciones de ATM bilateral o cuando la condición es de interés y esté presente en ambas arcadas (1).

El campo de visión más grande incluye toda la cabeza y ayuda a los médicos a visualizar las relaciones entre las bases del hueso, entre los dientes, así como anormalidades significativas en pacientes que requieren cirugía ortognática o aquellos con anomalías craneofaciales (1).

\section{Futuro para la TCCB}

La tecnología está cambiando constantemente y nuevas aplicaciones están adicionándose todos los días. La TCCB entonces proporciona algunos

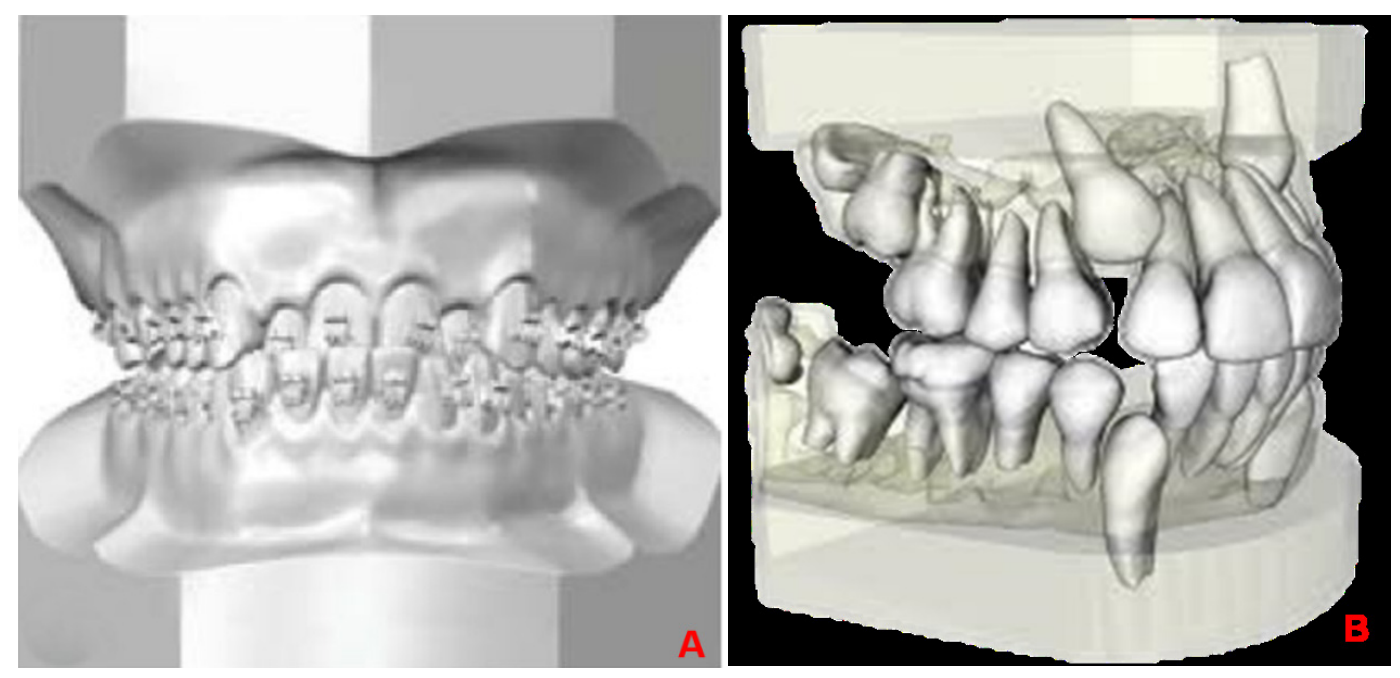

Figura 12. A: Modelos virtuales a partir del escaneamiento de la toma de impresión.

B: Modelos virtuales a partir de la TCCB. Fuente: Invisalign ${ }^{\mathrm{R}}$ 


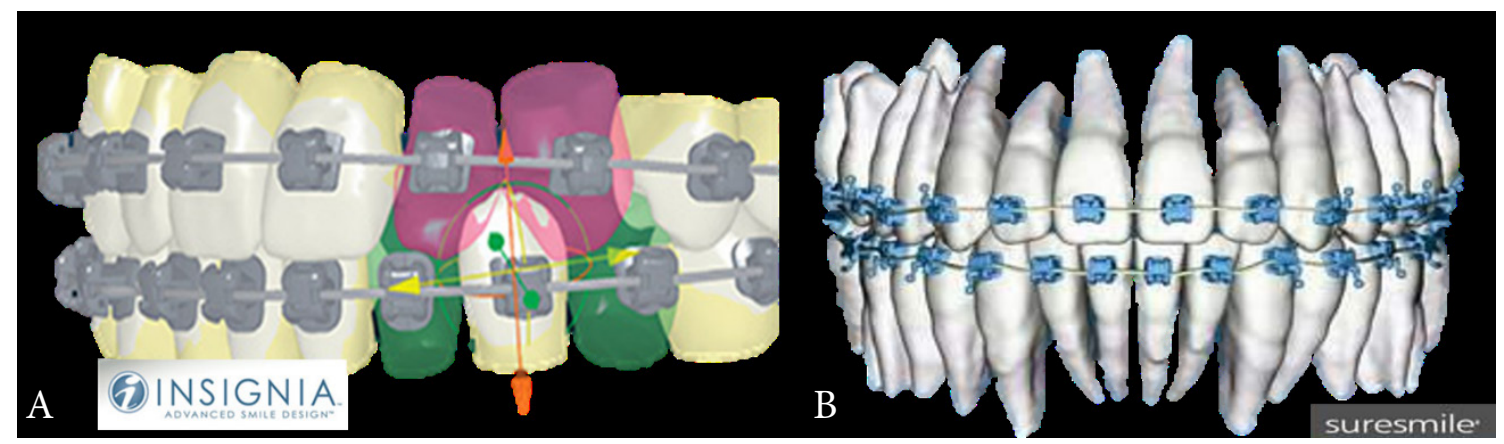

Figura 13. A: Insignia es un software completamente interactivo y sistema de aparatos a medida diseñado para dar a cada paciente una sonrisa verdaderamente personalizada. B: En lugar de doblar un arco de alambre con la mano, la compañía SureSmile utiliza una imagen 3D, simulaciones virtuales y arcos robóticamente doblados a medida para su tratamiento. Fuente: Insignia y SureSmile.

usos posibles en el futuro cercano, encontrándose actualmente en estudio parte de ésta nueva tecnología (44).

Modelos virtuales.- Los archivos base de la TCCB puede producir modelos virtuales 3D, sin necesidad de impresiones con alginato. Esto evitará la incomodidad del paciente y proporcionará al clínico más tiempo. Estos modelos tienen un alto valor diagnóstico comparado con los modelos digitales, ya que incluye no sólo las coronas, sino también las raíces, dientes retenidos, el desarrollo de los dientes y el hueso alveolar (Figura 12) (44).

Alineación Invisalign.- Es posible que en el futuro el proceso de fabricación de alineadores se realice a partir de archivos base de la TCCB. Además de eso, toda esta información tendrá la ventaja de ser transferida electrónicamente entre los laboratorios y los clínicos, especialmente ortodoncistas (44).

Cementado indirecto de brackets.- La construcción de modelos a partir de la TCCB, que se pueden utilizar en procedimientos de laboratorio, lo que requerirá un cementado indirecto (44).

Fabricación de brackets y alambres.- Los archivos de base de la TCCB se pueden utilizar para las necesidades de fabricación de brackets y alambres para cada paciente de forma individual (Figura 13) (44).

\section{CONCLUSIONES}

La TCCB en ortodoncia, se debe basar en la evaluación inicial y debe ser justificada en base a la necesidad de cada caso. Finalmente, el beneficio del paciente debe superar el riesgo de la radiación.

La literatura fue revisada y las principales aplicaciones de la TCCB en ortodoncia fueron destacadas, así como la evidencia actual y la comprensión de cada área. Es claro que, en la actualidad a pesar de la popularidad de la TCCB, no hay ninguna evidencia clara de que la información obtenida a partir de estas imágenes aumenta sustancialmente las decisiones de tratamiento clínico. Futuras investigaciones sobre TCCB deben centrarse en la interpretación de las imágenes obtenidas.

\section{Correspondencia:}

Gina Delia Roque-Torres

Av. Limeira 901, Piracicaba, São Paulo, Brasil.

Correo electrónico: ginart87@gmail.com

\section{REFERENCIAS BIBLIOGRÁFICAS}

1. AmericanAcademy of Oral andMaxillofacial Radiology. Clinical recommendations regarding use of cone beam computed tomography in orthodontics. Position statement by the American Academy of Oral and Maxillofacial Radiology. Oral Surg Oral Med Oral Pathol Oral Radiol. 2013; 116(2):238-57.

2. Hechler SL. Cone-beam CT: applications in orthodontics. Dent Clin North Am. 2008; 52(4):809-23.

3. Accorsi MAO. Velasco LG. Diagnóstico 3D em Ortodontia - A Tomografia Cone-beam aplicada. 1 ed. Nova Odessa: Editora Napoleão; 2001.

4. Silva MA, Wolf U, Heinicke F, Bumann A, Visser H, Hirsch E. Cone-beam computed tomography for routine orthodontic treatment planning: a radiation dose evaluation. Am J Orthod Dentofacial Orthop. 2008; 133(5):640.e1-5.

5. Larson BE. Cone-beam computed tomography is the imaging technique of choice for comprehensive 
orthodontic assessment. Am J Orthod Dentofacial Orthop. 2012; 141(4):402-6.

6. Hodges RJ, Atchison KA, White SC. Impact of conebeam computed tomography on orthodontic diagnosis and treatment planning. Am J Orthod Dentofacial Orthop. 2013; 143(5):665-74.

7. Van Vlijmen OJ, Kuijpers MA, Bergé SJ, Schols JG, Maal TJ, Breuning H, Kuijpers-Jagtman AM. Evidence supporting the use of cone-beam computed tomography in orthodontics. J Am Dent Assoc. 2012; 143(3):24152.

8. Brooks SL. TCCB Dosimetry: Orthodontic Considerations. Semin Orthod. 2009; 15(1):14-8.

9. Ustun C. Initiation of the adventure of X-rays in Turkey. Eur J Radiol. 2010; 75(3):343-5.

10. Adenwalla ST, Kronman JH, Attarzadeh F. Porion and condyle as cephalometric landmarks--an error study. Am J Orthod Dentofacial Orthop. 1988; 94(5):411-5.

11. Kapila S, Conley RS, Harrell WE Jr. The current status of cone beam computed tomography imaging in orthodontics. Dentomaxillofac Radiol. 2011; 40(1):2434.

12. Ramírez-Sotelo LR, Almeida S, Ambrosano GM, Bóscolo F. Validity and reproducibility of cephalometric measurements performed in full and hemifacial reconstructions derived from cone beam computed tomography. Angle Orthod. 2012; 82(5):827-32.

13. Armstrong C, Johnston C, Burden D, Stevenson M. Localizing ectopic maxillary canines-horizontal or vertical parallax? Eur J Orthod. 2003; 25(6):585-9.

14. Castellano, Di Santi. Reabsorciones radiculares de dientes anterosuperiores asociadas a caninos. Reporte de un caso clínico. Rev Ve Ort. 2009; 26(1,2):2-6.

15. Shellhart WC. Case report: Management of significant root resorption associated with maxillary canine impactation. Angle Orthod.1998; 68(2):187-92.

16. Bell GW, Rodgers JM, Grime RJ, Edwards KL, Hahn MR, Dorman ML, Keen WD, Stewart DJ, Hampton $\mathrm{N}$. The accuracy of dental panoramic tomographs in determining the root morphology of mandibular third molar teeth before surgery. Oral Surg Oral Med Oral Pathol Oral Radiol Endod. 2003; 95(1):119-25.

17. Park W, Park JS, Kim YM, Yu HS, Kim KD. Orthodontic extrusion of the lower third molar with an orthodontic mini implant. Oral Surg Oral Med Oral Pathol Oral Radiol Endod. 2010; 110(4):e1-6.

18. Honey OB, Scarfe WC, Hilgers MJ, Klueber K, Silveira AM, Haskell BS, Farman AG. Accuracy of cone-beam computed tomography imaging of the temporomandibular joint: comparisons with panoramic radiology and linear tomography. Am J Orthod Dentofacial Orthop. 2007; 132(4):429-38.

19. Korbmacher H, Kahl-Nieke B, Schöllchen M, Heiland M. Value of two cone-beam computed tomography systems from an orthodontic point of view. J Orofac
Orthop. 2007; 68(4):278-89.

20. Hechler SL. Cone-beam CT: applications in orthodontics. Dent Clin North Am. 2008; 52(4):809-23.

21. Korbmacher H, Kahl-Nieke B, Schöllchen M, Heiland M. Value of two cone-beam computed tomography systems from an orthodontic point of view. J Orofac Orthop. 2007; 68(4):278-89.

22. Santos ECA, Lara TS, Arantes FM, Coclete GA, Silva RS. Análise radiográfica computadorizada da reabsorção radicular apical após a utilização de duas mecânicas ortodônticas. R Dental Press Ortodon Ortop Facial 2007; 12(1):48-55.

23. Lund H, Gröndahl K, Gröndahl HG. Cone beam computed tomography for assessment of root length and marginal bone level during orthodontic treatment. Angle Orthod. 2010; 80(3):466-73.

24. Jian-Hong Yu, Kuang-Wei Shu, Ming-Tzu Tsai, JuiTing Hsu, Hsin-Wen Chang, Kuan-Ling Tung. A conebeam computed tomography study of orthodontic apical root resorption. J Dent Sci. 2013; 8(1):74-9.

25. Enhos S, Uysal T, Yagci A, Veli İ, Ucar FI, Ozer T. Dehiscence and fenestration in patients with different vertical growth patterns assessed with cone-beam computed tomography. Angle Orthod. 2012; 82(5):86874.

26. Yagci A, Veli I, Uysal T, Ucar FI, Ozer T, Enhos S. Dehiscence and fenestration in skeletal Class I, II, and III malocclusions assessed with cone-beam computed tomography. Angle Orthod. 2012; 82(1):67-74.

27. Gracco A, Lombardo L, Mancuso G, Gravina V, Siciliani G. Upper incisor position and bony support in untreated patients as seen on CBCT. Angle Orthod. 2009; 79(4):692-702.

28. Beckmann SH, Kuitert RB, Prahl-Andersen B, Segner D, The RP, Tuinzing DB. Alveolar and skeletal dimensions associated with lower face height. Am J Orthod Dentofacial Orthop. 1998; 113(5):498-506.

29. Garib DG, Henriques JF, Janson G, Freitas MR, Coelho RA. Rapid maxillary expansion-tooth tissue-borne versus tooth-borne expanders: a computed tomography evaluation of dentoskeletal effects. Angle Orthod. 2005; 75(4):548-57.

30. Smith T, Ghoneima A, Stewart K, Liu S, Eckert G, Halum S, Kula K. Three-dimensional computed tomography analysis of airway volume changes after rapid maxillary expansion. Am J Orthod Dentofacial Orthop. 2012; 141(5):618-26.

31. Kurt G, Sisman C, Akin E, Akcam T. Cephalometric comparison of pharyngeal airway in snoring and nonsnoring patients. Eur J Dent. 2011; 5(1):84-8.

32. Abramson Z, Susarla SM, Lawler M, Bouchard C, Troulis M, Kaban LB. Three-dimensional computed tomographic airway analysis of patients with obstructive sleep apnea treated by maxillomandibular advancement. J Oral Maxillofac Surg. 2011; 69(3):677-86. 
33. Alves M Jr, Baratieri C, Nojima LI, Nojima MC, Ruellas AC. Three-dimensional assessment of pharyngeal airway in nasal- and mouth-breathing children. Int J Pediatr Otorhinolaryngol. 2011; 75(9):1195-9.

34. Cevidanes LH, Styner MA, Proffit WR. Image analysis and superimposition of 3-dimensional conebeam computed tomography models. Am J Orthod Dentofacial Orthop. 2006; 129(5):611-8.

35. Choi JI, Cha BK, Jost-Brinkmann PG, Choi DS, Jang IS. Validity of palatal superimposition of 3-dimensional digital models in cases treated with rapid maxillary expansion and maxillary protraction headgear. Korean J Orthod. 2012; 42(5):235-41.

36. Cağlayan F, Tozoğlu U. Incidental findings in the maxillofacial region detected by cone beam CT. Diagn Interv Radiol. 2012; 18(2):159-63.

37. Drage N, Rogers S, Greenall C, Playle R. Incidental findings on cone beam computed tomography in orthodontic patients. J Orthod. 2013; 40(1):29-37.

38. Ahmed F, Brooks SL, Kapila SD. Efficacy of identifying maxillofaciallesions in cone-beam computed tomographs by orthodontists and orthodontic residents with third-party software. Am J Orthod Dentofacial Orthop. 2012; 141(4):451-9.

39. Smith BR, Park JH, Cederberg RA. An evaluation of cone-beam computed tomography use in postgraduate orthodontic programs in the United States and Canada. J Dent Educ. 2011; 75(1):98-106.
40. Hodges RJ, Atchison KA, White SC. Impact of conebeam computed tomography on orthodontic diagnosis and treatment planning. Am J Orthod Dentofacial Orthop. 2013; 143(5):665-74.

41. Honey OB, Scarfe WC, Hilgers MJ, Klueber K, Silveira AM, Haskell BS, Farman AG. Accuracy of cone-beam computed tomography imaging of the temporomandibular joint: comparisons with panoramic radiology and linear tomography. Am J Orthod Dentofacial Orthop. 2007; 132(4):429-38.

42. Shim JJ, Heo G, Lagravère MO. Assessment of skeletal maturation based on cervical vertebrae in TCCB. Int Orthod. 2012; 10(4):351-62.

43. Lotti RS, Machado AW, Mazzieiro ET, Júnior JL. Aplicabilidade científica do método dos elementos finitos. R Dental Press Ortodon Ortop Facial. 2006; 11(2):35-43.

44. Agrawal JM, Agrawal MS, Nanjannawar LG, Parushetti AD. CBCT in Orthodontics: The wave of Future. J Contemp Dent Pract. 2013; 14(1):153-7.

Recibido: 16/10/2014

Aceptado: 12/01/2015 